\title{
STUDIES ON ADRENOCORTICAL EOSINOPENIA: A CLINICAL AND STATISTICAL EVALUATION OF FOUR-HOUR EOSINOPHIL RESPONSE TESTS ${ }^{1,2}$
}

\author{
BY WILLIAM R. BEST, ROBERT C. MUEHRCKE, ${ }^{3}$ AND ROBERT M. KARK \\ (From the Department of Medicine, University of Illinois College of Medicine, and the Illinois \\ Research and Educational Hospitals, Chicago, Ill.)
}

(Submitted for publication February 12, 1952; accepted May 19, 1952)

As early as 1914 Schwarz (1) suspected an inverse relationship between adrenal activity and the level of circulating eosinophils. Twenty-five years later Dalton and Selye (2) noted eosinopenia following stress in animals and related it to release of adrenal cortical hormones. More recently Thorn and his associates $(3,4)$ observed a prompt decrease in circulating eosinophils in healthy persons, and in patients, following a single injection of pituitary adrenocorticotropic hormone (A.C.$T . H$. or corticotropin). The greatest reduction in eosinophils was seen four hours after injection and was related to secretory activity of the adrenal cortex. In a study of 40 people with normal adrenal activity Thorn, Forsham, Prunty, and Hills (5) reported that the mean drop in circulating eosinophils at four hours was $70 \%$ below preinjection levels. In all instances the drop in circulating eosinophils was greater than $45 \%$. This was in sharp contrast to what was seen in patients with Addison's disease, where they noted little change in circulating eosinophils after injection of corticotropin. Thorn, therefore, proposed that the eosinophil response to A.C.T.H. should be used as a test in the diagnosis of Addison's disease. He and Forsham suggested (6) that a fourhour post-injection ". . . fall of $50 \%$ or more of the circulating eosinophils eliminates the diagnosis of adrenal cortical insufficiency," and they indicated that an inadequate response, of less than $50 \%$ fall, may represent true adrenal cortical insuffciency.

A transitory eosinopenia also develops in animals after injection of epinephrine. On the basis

1 Supported in part by a grant from Armour and Company, Chicago, Ill.

2 Presented at the 24th Annual Meeting of the Central Society for Clinical Research, November 2 and 3, 1951, Chicago, III.

${ }^{3}$ Armour Research Fellow in Medicine. of extirpation and electrical stimulation studies on dogs by Hume and Wittenstein $(7,8)$, Recant, Hume, Forsham, and Thorn (9) postulate that the hypothalamus, pituitary, and adrenal cortex are successively stimulated to produce epinephrine eosinopenia. They advocate a four-hour eosinophil response test to parenteral epinephrine for estimating the functional activity of the pituitaryadrenal axis in man.

In this laboratory, working with Samter, we found that oral ephedrine is also capable of producing transient eosinopenia in man (10-13). This phenomenon has been observed independently by Abelson and Moyes (14). While the fourhour response of eosinophils to epinephrine or ephedrine has been used mainly in testing individual patients, it has also been used to measure pituitary-adrenal activity in various physiological states, such as infancy (15), old age (16), following operations (17), and to assess groups of people ill with different types of disease processes such as chronic alcoholism (18) and acute gout (19).

In order to test the validity of the different eosinophil response tests as clinical tools in diagnosis and as indices of activity of the hypothalamus, pituitary, or adrenal cortex, observations were made on a large number of patients; among whom were many with conditions thought to be related to abnormalities of the pituitary-adrenal axis. The data obtained were subjected to statistical analysis and are reported below.

\section{METHODS}

Selection of patients. Patients were selected who had Addison's disease, known pituitary tumors, suspected hypopituitarism, prolonged inanition, cachexia, or unusual eosinophilia. Others were chosen at random from hospital admissions over a two-year period, and a few healthy persons were included in the study. In all, 284 individuals were studied. Their ages ranged from 12 
to 72 years. Eleven $\%$ were in their teens and the remainder were rather evenly distributed between 20 and 70 years, the mean age being 40 years. Fifty-seven $\%$ were female. The most frequent diagnoses included cardiovascular disease $(15 \%)$, diabetes mellitus $(9 \%)$, rheumatoid arthritis $(7 \%)$, neoplasms and leukemia $(7 \%)$, bronchial asthma ( $6 \%)$, chronic and subsiding infections, miscellaneous pulmonary conditions, and psychoneurosis (4\% each). There were nine patients who were thought to have Addison's disease, but only two were demonstrated to have true adrenocortical insufficiency. Five patients had tumors in, or encroaching upon, the pituitary body. Hypopituitarism was suspected in seven patients ill with marked weight loss but confirmed in none.

Technique of testing. Patients believed to be in acute stress due to their illness or its treatment were not tested. Patients with significant hypertension, coronary artery disease, or arteriosclerosis were not tested with epinephrine or ephedrine.

Tests were scheduled so as not to coincide with other major diagnostic or therapeutic procedures. Regular ward activities were not restricted. When feasible, daily medications were withheld until completion of the test. In all patients fasting venous blood was drawn at 8:00 a.m. and placed in a tube with heparin.

Following this the patient was given tablets of ephedrine sulfate, $45 \mathrm{mg}$. orally, or corticotropin, 20-25 mg. intramuscularly or green placebo capsules, orally. Epinephrine, when given, was administered in amounts of 0.2 to $0.4 \mathrm{mg}$. intravenously over a one-hour period, or $0.3 \mathrm{mg}$. subcutaneously. A light breakfast was allowed, but lunch was withheld until the four-hour blood specimen had been drawn at noon. For each test the same individual made both eosinophil counts. Results of the test were recorded as per cent decrease in eosinophils after four hours, below the fasting level.

Repeat tests on a patient were usually scheduled two or more days apart. The sequence with repeated tests was not always the same, but generally two or more tests with ephedrine sulfate or epinephrine would be followed by placebo tests, and finally corticotropin tests would be made. In all, 702 four-hour response tests were carried out.

Technique of eosinophil counts. Chamber eosinophil counts were made using the phloxine-propylene glycol stain of Randolph (20) or as modified by Henneman, Wexler, and Westenhaver (21). Four standard 0.9 mm. Levy chambers (two hemocytometers) were filled from a single pipette after a 1:10 dilution. The total number of cells counted in the entire ruled area of the four chambers was multiplied by 2.78 to give the number of eosinophils per mm. of blood.

\footnotetext{
4 Corticotropin was obtained through the courtesy of: Armour and Company, Chicago (25 mg. dose) and Wilson and Company, Chicago (20 mg. dose). A small quantity of corticotropin from an experimental batch made by another pharmaceutical company failed to produce eosinopenia. Studies with this preparation were not included in statistical analyses.
}

Statistical analysis. Standard techniques of quantitating variation and significance of group differences as outlined in Snedecor (22) were employed. Fiducial limits of the mean signify the $95 \%$ confidence limits.

\section{RESULTS}

\section{Intrinsic error of single eosinophil counts}

The intrinsic error of enumeration and physiologic changes in eosinophil level have been outlined previously by one of us with Samter (11), and have been further emphasized by Fisher and Fisher (23). Unfortunately, these sources of error have not been appreciated by all investigators utilizing this technique.

From the point of view of the present study, it was necessary to investigate the intrinsic error of chamber eosinophil counts in more detail than had been done previously so that valid statistical conclusions could be made on eosinophil counts obtained in the tests. Therefore, the standard deviation of a group of four individual chamber eosinophil counts was calculated for each of 500 blood specimens from this series. The first 400 were taken consecutively; the last 100 included only counts greater than 275 cells per mm. as there were already sufficient observations regarding the lower mean counts. These standard deviations are plotted against the respective means of the four chamber counts as illustrated in Figure 1.

These values are compared with the curve of maximum possible standard deviation. This curve was plotted by inspection of all possible combinations of counts in four chambers which can yield representative mean eosinophil counts. The fewer the number of chambers in such a computation, the more markedly will this limiting factor restrict the correspondence of observed values as compared to the theoretical dispersion if an unlimited number of chambers were used. Inspection of this curve shows that maximal standard deviations were reached only when the mean eosinophil counts ranged from zero to 15 cells per mm. ${ }^{8}$.

The observed standard deviations were also compared with a theoretical curve for one standard deviation of counts which was derived from the formulae of Berkson, Magath, and Hurn (24). By inspection of the data it can be seen that the observations are not equally distributed above and below the theoretical curve, the observed standard deviations being generally less than predicted, 


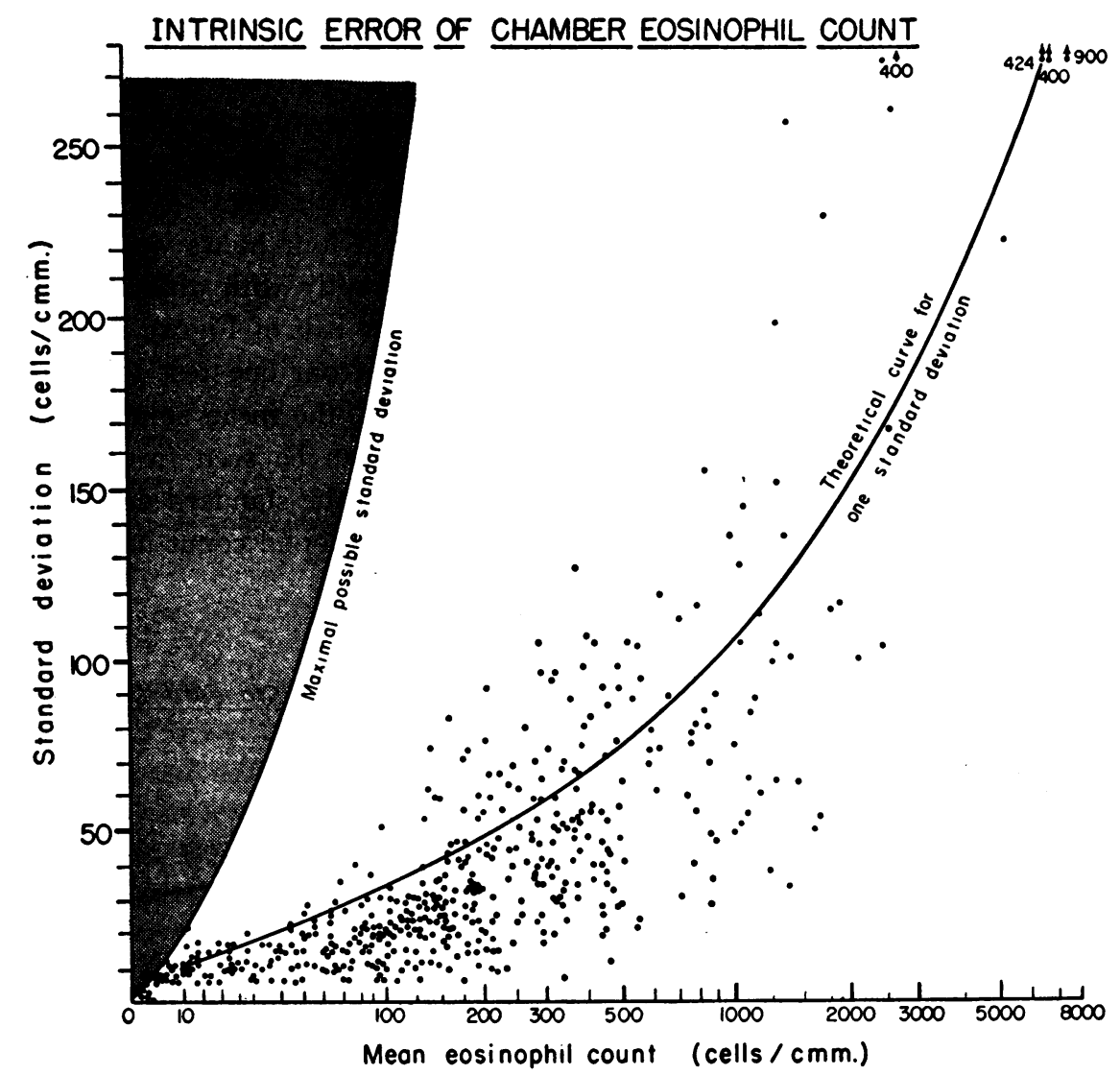

Fig. 1. Instrinsic Error of Chamber Eosinophil Counts

Each dot represents a series of four eosinophil counts from separate $0.9 \mathrm{~mm} .^{3}$ chambers filled by a single 1:10 blood-stain dilution. The calculated standard deviation for each such series is plotted against the mean eosinophil count of that series. Five hundred blood samples are thus represented. The theoretical curve for one standard deviation at any eosinophil level is derived mathematically from the formula of Berkson, Magath, and Hurn (24). The curve of "maximal possible deviation" was obtained from inspection of all possible combinations of counts from four chambers which can yield selected mean eosinophil counts. As only a few observations coincide with this curve, it does not appear to be an important limiting factor in the distribution of these data. The few dots appearing to exceed the maximal possible deviation actually coincide with it. Limited space on the graph necessitates this apparent discrepancy.

though having a parallel distribution. In spite of these apparent discrepancies, it seems advisable to use the theoretically derived values in assessing

TABLE I

Intrinsic errors of chamber eosinophil counts using one pipette with 1:10 dilution and four $0.9 \mathrm{~mm} .^{3}$ chambers

True eosinophil
level of sample
25 cells $/ \mathrm{mm}$.
50 cells $/ \mathrm{mm}$.
100 cells $/ \mathrm{mm}$.
200 cells $/ \mathrm{mm}$.
400 cells $/ \mathrm{mm}$.

Range for $95 \%$ of chamber counts on sample

$8-42$

26-74

65-135

148-252

$323-477$ the probable intrinsic errors of the eosinophil count. ${ }^{5}$

5 Berkson, Magath, and Hurn (24) have pointed out the unconscious tendency towards faulty chamber counting by technicians and physicians. In their own studies they had to photograph each ruled area of the counting chamber and had to punch a hole through the photographic image of each cell to ensure absolute accuracy in cell counts made for statistical analyses.

In addition to the universal difficulty of counting objects as seen through the microscope, there are five situations encountered in the eosinophil counting chamber where "judgment" may be substituted for complete ob- 

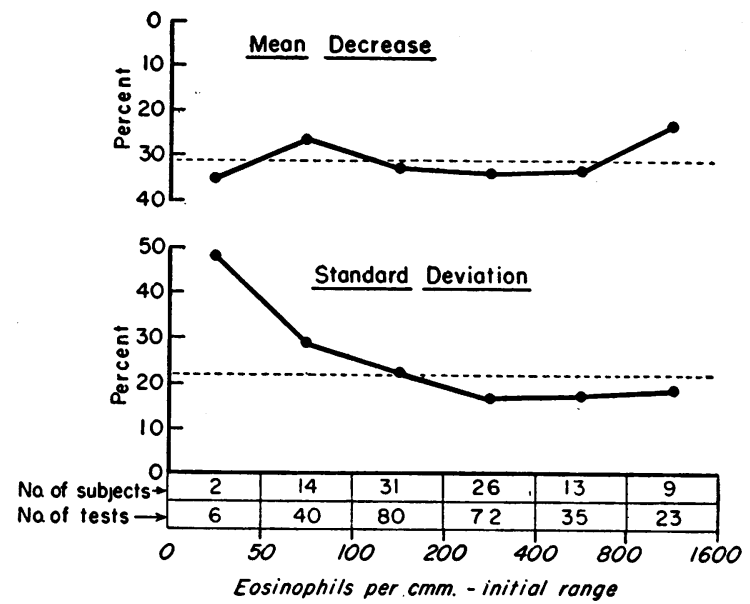

Fig. 2. Trend and Variability of Repeated EphedRINE RESPONSE TESTS

Mean per cent decrease (above) and standard deviation (below) of repeated eosinophil response tests to $45 \mathrm{mg}$. ephedrine for each subject have been averaged by groups and plotted against initial eosinophil levels (abscissa).

Table I presents the theoretical coefficient of variation and the two standard deviation limits ( $95 \%$ of observations) for several representative true eosinophil levels when all four chambers are used to compute the count, as was the case for all response tests reported herein. The coefficient of variation is greatest with low eosinophil levels despite the smaller range of cell counts.

jectivity. These are: (1) differentiation of eosinophils from debris, (2) differentiation of eosinophils from neutrophils if insufficient time is allowed for staining, (3) differentiation of eosinophils from eosinophilic staining erythrocytes which have been altered by incomplete removal of acetone from pipettes, (4) philosophy of enumeration when some eosinophils are clumped, and (5) determination of whether a given cell is inside or outside of the ruled area. Needless to say, one should examine the preparation under a higher power when doubt exists about the first three possibilities, and a new preparation should be made if the third or fourth exists. The fifth is relatively uncommon. Inasmuch as the total number of cells counted is usually small, even with four chambers, a difference of a few cells in a preparation can make an appreciable difference in comparison of mean counts and an even greater difference in calculation of the standard deviation. Thus, in our studies, if "judgment" were exercised in selecting or rejecting only two eosinophils per preparation of four chambers, and if this "judgment" were conditioned, as it usually is from training, by the desire to have consistent counts it would make a difference of approximately two cells per $\mathrm{mm}^{2}$ in the standard deviation and would bring the observed values into line with the theoretical curve.

\section{Variable response to ephedrine tests in the same subject}

Repeated tests to oral ephedrine were performed in 95 subjects ; 55 having two; 17 , three; 21 , four ; and 3 , five such tests. The mean decrease of eosinophils at four hours was $30.7 \%$ and did not vary significantly with different initial eosinophil levels (upper half of Figure 2).

Variation from one test to the next was frequently great, the mean standard deviation being $22.1 \%$. It can be seen from the lower half of Figure 2 that the standard deviation decreased as the initial eosinophil count increased. Variability

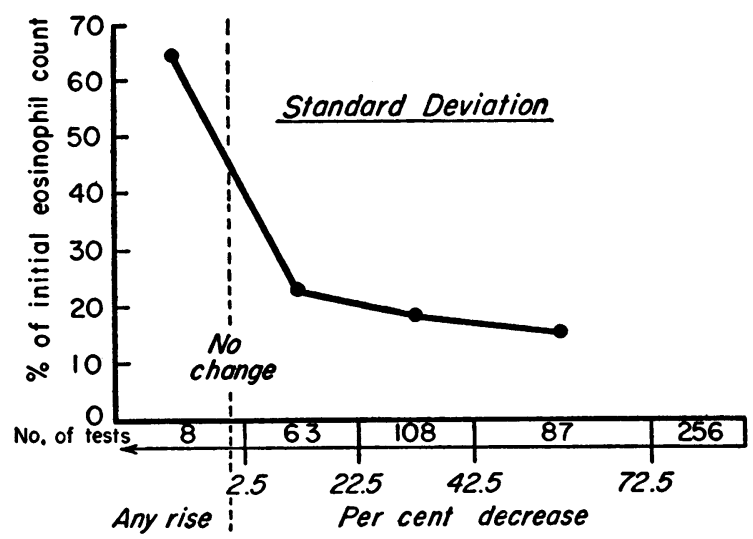

Mean change over initial eosinophil.count

Fig. 3. Variability of Repeated Ephedrine Tests According to Mean Degree of Response

Standard deviation of repeated eosinophil response tests (ordinate) to $45 \mathrm{mg}$. ephedrine for each subject have been averaged for each group and plotted against the mean percentage change in eosinophils after testing (abscissa).

of repeated tests was particularly marked with starting counts below 100 cells per mm. ${ }^{3}$. With higher initial counts the standard deviation remained at about $18 \%$.

The standard deviation of repeated tests in these same subjects was also studied with relation to grouped mean levels of response (Figure 3.). This figure shows that the greater the tendency towards eosinopenic response to this test, the more consistent are the repeated tests.

Figure 4 shows that there was $2.4 \%$ greater mean response of all second over first tests. When they were repeated at very short intervals, second tests showed significantly less response than first 
tests, but if three or more days elapsed between procedures, there was more than a $10 \%$ increase.

Although insufficient data of this type were collected for similar statistical analysis of repeated tests of subjects to epinephrine, corticotropin, and placebos, we have noted that these tests are also not accurately reproducible, and their degree of variability appears to be correlated with the same factors.

\section{Comparative response to corticotropin, ephedrine, and placebos}

The mean response to a given stimulus by each subject was analyzed with that of all other subjects so tested (excluding tests on patients with Addison's disease). Figure 5 shows the mean, the fiducial limits of the mean, the standard deviation, and the $95 \%$ confidence limits for all fourhour observations of the percent change in eosinophils from pre-treatment levels. These are grouped for tests with placebo, with ephedrine, and with corticotropin. The mean eosinophil decrease with placebo was $10.5 \%$; with ephedrine, $40.8 \%$; and with corticotropin, $62.0 \%$. Values encompassed by fiducial limits of the respective means are widely separated.

It should be pointed out that in individual instances this difference may not be evident inas-

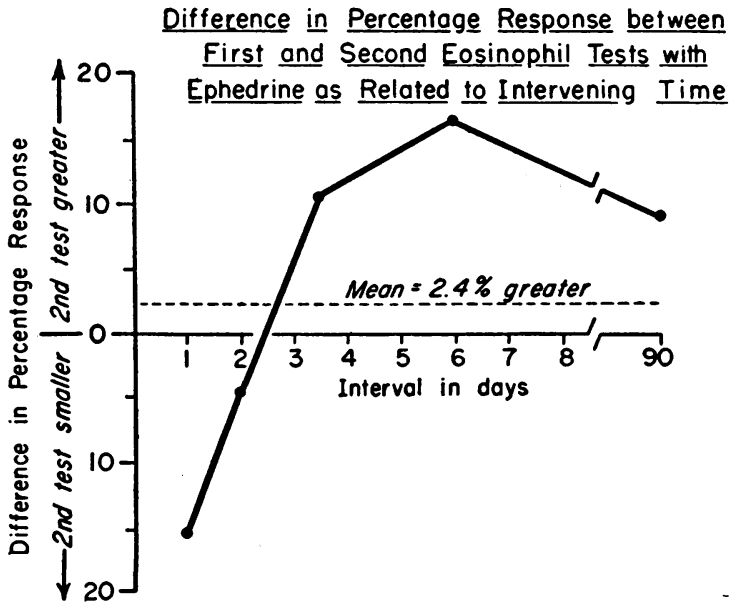

Fig. 4. Difference in Response between First and Second Ephedrine Tests

Percentage difference between first and second eosinophil response tests to $45 \mathrm{mg}$. ephedrine are related to the number of intervening days. The interval in 21 subjects was one day; in 19, two days, in 18 , three or four days; in 18 , five to seven days; and in 13 , eight to ninety days.
FOUR HOUR EOSINOPHIL RESPONSE TESTS IN MISCELLANEOUS MEDICAL SUBJECTS

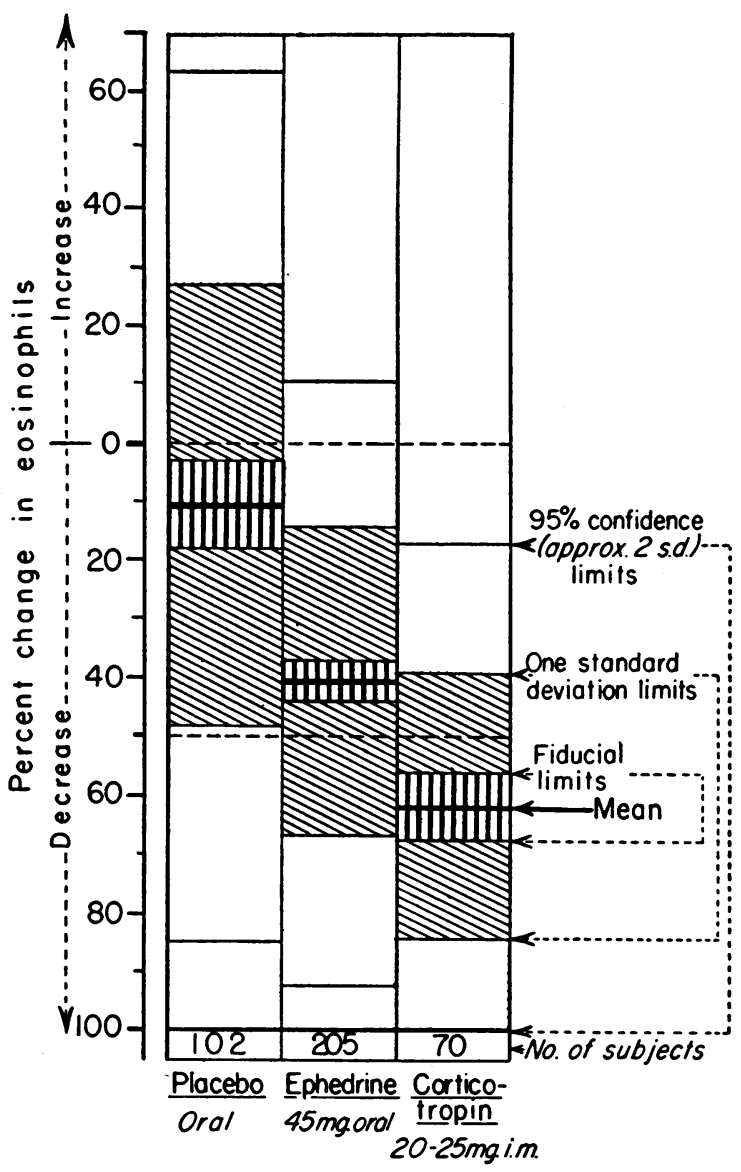

Fig. 5. Eosinophil Response Tests to Three Agents

Mean, fiducial limits of the mean, and one and two standard deviation limits are indicated for four-hour eosinophil response tests to placebo capsules, $45 \mathrm{mg}$. ephedrine, and $20-25 \mathrm{mg}$. corticotropin in a variety of patients.

much as the one standard deviation limits of all three groups overlap considerably. These limits encompass approximately two-thirds of observations for each group. Almost one-sixth of subjects given placebos showed four-hour eosinopenia of $50 \%$ or greater and in approximately one-sixth of non-Addisonian individuals the eosinophil levels fell less than $40 \%$ four hours after injection of corticotropin.

The mean levels of the three groups of tests and the standard deviations for each stimulus were analyzed in relation to the initial eosinophil level. The degree of response to placebo and cortico- 


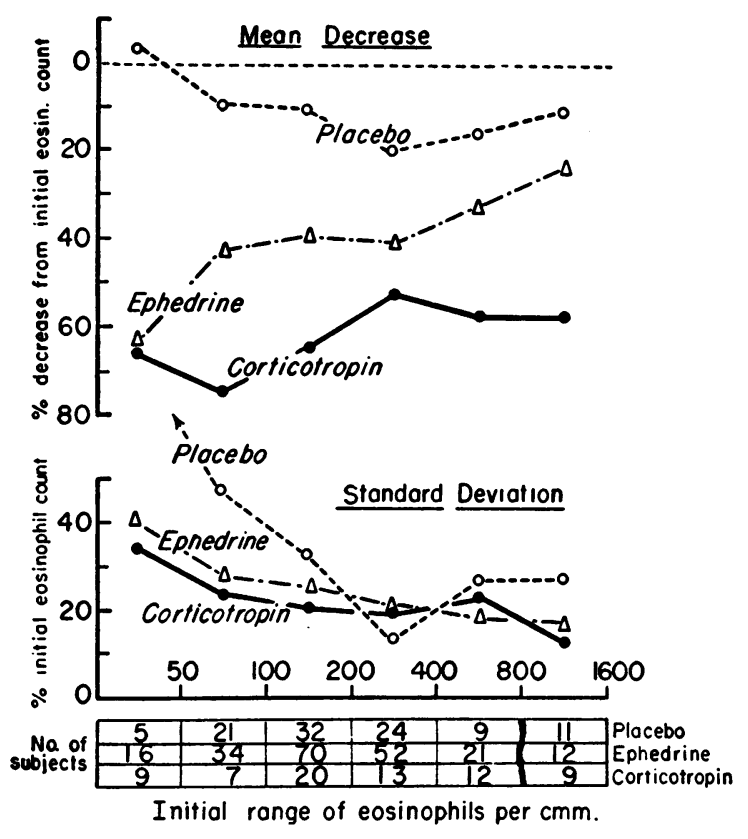

Fig. 6. Trend and Distribution of Response to Three Agents

Mean per cent decrease (above) and standard deviation (below) of eosinophils in all subjects after four-hour response tests to placebo capsules, $45 \mathrm{mg}$. ephedrine, and 20-25 mg. corticotropin are grouped according to level of pre-test circulating eosinophils (abscissa).

tropin was little influenced by the mean eosinophil level, though there was a suggestion of decreasing response with high levels in tests using ephedrine (Figure 6). In all instances the standard deviations for each stimulus were greater with low than with higher counts.

\section{Examples of variable responses in individual patients}

Examples of the variability of the responses to the different tests are given below: The eosinophil level of a patient with refractory anemia fell $69 \%$, $51 \%, 56 \%$, and $35 \%$ and increased $7 \%$ after repeated tests to placebos; they fell $45 \%, 49 \%$, and $34 \%$ after ephedrine testing; and they dropped $53 \%$ after injection of corticotropin. The eosinophil level of a young diabetic patient fell only $22 \%$ after corticotropin injection, but after ephedrine the eosinophil levels fell by $76 \%, 50 \%, 53 \%$, and $64 \%$ on different occasions. Two patients with hypothyroidism were tested before and during thyroid therapy. The first of these had a $26 \%$ and a $29 \%$ fall with ephedrine before therapy, a
$50 \%$ decrease the second week, and a $26 \%$ drop the third week of thyroid therapy. The second patient had a $21 \%$ decrease and a $10 \%$ rise before therapy, a $52 \%$ fall one week after thyroid extract had been started, and $26 \%$ and $11 \%$ decrease two weeks later.

Numerous other examples of wide variation in response to repeated tests with the same agent and seemingly paradoxical responses in comparison with tests to more than one agent could be cited.

\section{Failure of response to corticotropin}

Twenty-three subjects of the 76 tested with corticotropin at first failed to show a decrease of eosinophils exceeding 50\%. Two of these had proven Addison's disease. In the first patient the eosinophils dropped $5 \%, 2 \%$, and $23 \%$ in three separate tests with corticotropin and increased $3 \%$ and $8 \%$ after ephedrine. In the second patient there was a $4 \%$ and an $11 \%$ rise after corticotropin, a $12 \%$ fall after ephedrine and an $8 \%$ drop after injection of epinephrine.

One patient, ill with dermatomyositis had been tested during the time he was receiving cortisone and presumably he did not respond because of a temporary adrenocortical insufficiency. Five patients were tested with what turned out to be an inferior batch of corticotropin. Data from these six patients were not included in the statistical analyses. It is possible that some of the other failures were partially due to preparations of substandard potency as discussed later.

The subjects in whom initial response to corticotropin was "inadequate" had a greater than $50 \%$ eosinopenia after repeat testing with corticotropin and/or ephedrine. Unfortunately, circumstances beyond our control interfered with retesting five such patients. There was no clinical evidence, nor biochemical data to suggest adrenocortical insufficiency in any of these subjects, and it seems likely that a greater than $50 \%$ eosinopenia would have been noted in each of them with retesting.

\section{Response to ephedrine in pituitary disease}

It is well known that up to three quarters of the pituitary gland may be destroyed with few or no symptoms of hypopituitarism (25). 
In the present study five patients with tumors arising within or infringing upon the sella turcica were given eosinophil response tests to ephedrine. Quantitative histologic data concerning viable pituitary tissue are not available on these cases. Responses varied from a $24 \%$ increase to a $65 \%$ decrease of eosinophils, with a mean fall of $38 \%$.

\section{Response to ephedrine in conditions of marked weight loss}

Fifteen tests were performed on seven patients showing marked weight loss due to anorexia nervosa. Results ranged from a $9 \%$ to an $84 \%$ decrease after ephedrine with a mean drop of $51 \%$. Six tests were done on four patients with carcinomatosis and cachexia. In them there was an $8 \%$ to a $100 \%$ fall in eosinophils and a mean drop of $41 \%$. There was, therefore, no significant difference between the subjects of this group and those with other chronic illnesses insofar as their response to ephedrine is concerned.

\section{DISCUSSION}

\section{Technical errors in eosinophil response tests}

These studies amply demonstrate the lack of precision inherent in the four-hour eosinophil response tests. The errors of single eosinophil counts are basic to a consideration of variation in such tests. Some of the human errors of enumeration have been mentioned in footnote number 5 of this paper. In addition there is a chance variation related to the total number of cells counted. This theoretical error has been discussed previously (11) and is represented in Figure 1 and Table $I$ for a single pipette and both sides of two standard hemocytometers. Exact accuracy of cell counts is hard to obtain with the best will in the world, but the common error of counting insufficient cells (using only one or two sides of a single hemocytometer) is easily avoided. We recommend at least four standard chambers (two hemocytometers), or preferably, four large Fuchs-Rosenthal chambers.

It is seen from Table I that the theoretical coefficient of variation for single specimens is greatest with low eosinophil counts. The error of comparing successive counts would be expected to reflect a similar relationship to initial eosinophil level. This was borne out in the standard devia- tions of Figure 2 for repeated tests in the same subject and in Figure 6 for the comparison of mean responses in many subjects. Thus, the greatest variation is noted with the lowest initial counts.

With higher initial eosinophil counts the intrinsic errors of counting became of less importance. In spite of this, a standard deviation of approximately $18 \%$ persists for repeated tests on subjects with high initial levels (Figure 2). This variability is apparently related to short term fluctuations in eosinophil level as described by Rud (26) as well as to alterations in the physiological state of the subjects. In order to minimize these factors it is important to see that the subject is under the least possible stress during the test.

As shown in Figure 3 the standard deviation of repeated tests was greater in subjects showing slight or no mean response than in those with a marked fall in eosinophils. This may be at least partially explained by the simple arithmetic fact that to yield mean values approaching a $100 \%$ decrease of eosinophils, values for repeated tests must be more closely grouped than is necessary for cases of lesser response.

The tendency towards greater response of second over first tests, particularly when separated by more than three days, as shown in Figure 4, may seem surprising. We feel this tendency is not significant inasmuch as early in the study repeat tests were only done on those subjects failing to show significant eosinopenia. In these patients, initial values were often lower than their mean response to subsequent repeated tests. More significant is the comparison of successive tests as related to the interval between tests. It appears that the responsiveness to ephedrine is impaired for several days after each test. We do not know whether this represents tachyphylaxis, fatigue, or adaptation. In any case, when tests are repeated they should be run at least three or more days apart.

\section{Response to corticotropin in Addison's disease}

The four-hour eosinophil response to a single in jection of $25 \mathrm{mg}$. corticotropin, though a valuable tool in the diagnosis of Addison's disease, is certainly not infallible. We know of no instance in which a patient with Addison's disease has developed a significant eosinopenia to this test, but 
we and others (27) have observed several patients without Addison's disease who failed to respond to injection of corticotropin. Therefore, failure of response to a single test with corticotropin cannot be considered diagnostic of Addison's disease.

It must be pointed out that in the past some experimental and commercial preparations of corticotropin were poor stimulators of the adrenal gland. Most of the corticotropin used in this study was tested for potency in healthy individuals. Nevertheless variations of potency may have been responsible for a few of the subnormal responses observed after injection of corticotropin.

In the event of an inadequate response repeated tests with corticotropin are indicated. The intravenous test (28), which gives a more powerful stimulus to the adrenal cortex than the intramuscular test, should be used in re-testing.

\section{Epinephrine, ephedrine, and the hypothalamic- pituitary-adrenal axis}

In the beginning of our study we used epinephrine as a stimulus for producing transitory eosinopenia. After performing over 50 tests with this agent (11) we changed to oral ephedrine which has very similar pharmacologic and physiologic effects on man; the main difference, according to Gaddum and Kwiatkowski (29), is that ephedrine is tachyphylactic and is less readily destroyed in the body. Within the broad limits of variability for the test, ephedrine is seen to produce approximately the same degree of eosinopenia in individual subjects as do the conventionally employed doses of epinephrine.

The clinical significance of the eosinophil response tests to epinephrine and ephedrine depend on whether or not these agents induce eosinopenia through successive stimulation of the hypothalamus, pituitary, and adrenal cortex in man. As far as we have been able to ascertain, Hume's work regarding the epinephrine effect on the hypothalamus of animals has not been repeated for either epinephrine or ephedrine (30). In the rat the hypothalamus is not a necessary part of the axis for the production of epinephrine eosinopenia. McDermott, Fry, Brobeck, and Long (31) demonstrated that application of minute amounts of epinephrine directly to a pituitary gland transplanted into the anterior chamber of the rat's eye would induce eosinopenia, whereas parenteral injection of the same quantity was without effect.

Sayers (32) has recently suggested that “. . epinephrine does not discharge A.C.T.H. by a direct action on the adenohypophysis or via a neural link to the gland, but rather acts to increase peripheral utilization of cortical hormones." In this regard, Robinson (33) has studied a patient with rheumatoid arthritis, made unresponsive to corticotropin by cortisone. When epinephrine was given to him there was an appreciable drop in eosinophil count. Three of our patients with Addison's disease did not show significant eosinophil responses to epinephrine while on cortisone and two responded (three of these cases were recently added to the series, and were not considered in previous discussions).

However, we have studied five patients with carcinoma of the prostate after complete adrenalectomy while they were receiving cortisone (34). Following $0.3 \mathrm{mg}$. epinephrine subcutaneously, eosinophils decreased by 36 to $78 \%$ with a mean fall of $61 \%$. Little change in level of circulating eosinophils followed injection of saline or corticotropin.

As long as the mechanisms of epinephrine and ephedrine induced eosinopenia are not fully clarified, the interpretation of inadequate response to these agents as indicative of disturbed pituitary or adrenal function is untenable.

\section{Is the four-hour eosinophil response test to epi- nephrine or ephedrine a useful clinical tool?}

Thorn and Forsham (6) write that ". . . a fall of $50 \%$ or more in circulating eosinophils (after injection of epinephrine) excludes the presence of serious pituitary A.C.T.H. or adrenal cortical insufficiency." However, a large number of physicians interpret the test erroneously, and believe that an inadequate response of less than $50 \%$ fall indicates disease or relative dysfunction of the hypothalamus, pituitary, or adrenal cortex.

The fact that more than half of our tests with epinephrine or ephedrine in healthy people and in patients showed less than a $50 \%$ eosinopenic response attests to the error of such an interpretation. It is obvious that over half of the patients did not have serious dysfunction of the pituitary or adrenal glands. In practically none of the pa- 
tients were there other symptoms or findings suggestive of hypopituitarism or neurologic disorders.

We have also shown that neoplastic disease of the pituitary does not necessarily interfere with the eosinopenic response to ephedrine, and Almy, Laragh, and Cohen (35) have noted similar observations. In patients with anorexia nervosa or inanition from other causes we have also recorded large eosinopenic responses to epinephrine and ephedrine. Many observers have postulated that functional hypopituitarism exists in such cases, though others deny this possibility (25). In addition, adrenalectomized patients have responded to epinephrine in the presence of cortisone. Thus, the diagnostic value of negative tests to epinephrine or ephedrine in individual subjects appears to be practically nil. Positive tests to these agents in patients (who are not receiving cortisone) would appear to rule out Addison's disease.

What is the value of these tests in the study of particular diseases or physiologic states? To be certain that the response to an agent such as epinephrine differs significantly from that seen in normals, a control group should be simultaneously tested and the results subjected to statistical analysis. This can be done through use of a " $t$ " test or by the graphic method of Figure 5, in which the shaded areas encompassed by the fiducial limits of the respective means are separated and indicate significant differences of response. If these areas had overlapped, one could not say that the differences between the means were significant, and accumulation of further data might or might not indicate significant differences.

Nevertheless, even though an investigator demonstrates significant deviation of a particular group from normal in tests with epinephrine or ephedrine the interpretation of this deviation as differences in adrenal or pituitary function is still open to question. Proper assessment of functional endocrine changes in different groups of subjects must await assay of adrenocorticotropic hormone and/ or adrenal steroids in the blood before and after these stimuli.

\section{CONCLUSIONS}

Clinical and statistical analysis of 702 four-hour eosinophil response tests to corticotropin, ephedrine, epinephrine, or placebos in 284 normal and miscellaneous medical subjects lead us to conclude:
1. Despite careful technique, individual eosinophil response tests are very inaccurate.

2. Failure of response to corticotropin (A.C.T.H.) is suggestive of Addison's disease. Repeated four-hour, single dose tests and/or more vigorous attempts at adrenal cortical stimulation should be employed before failure of eosinopenia is attributed to adrenocortical insufficiency.

3. Greater than $50 \%$ drop of eosinophils has been noted following epinephrine or ephedrine in patients with pituitary tumors and in patients adrenalectomized and receiving small doses of cortisone. Responses of less than $50 \%$ are seen in a large number of patients with unrelated pathological conditions. Tests with these substances are therefore of little value in the diagnosis of adrenal, hypothalamic, or pituitary disease, and do not accurately assess the functional capacity of these organs at the time of examination.

\section{REFERENCES}

1. Schwarz, E., Die Lehre von der allgemeinen und örtlichen "Eosinophilie." Ergebn. d. allg. Path. u. path. Anat., 1914, 17, (Part 1), 137.

2. Dalton, A. J., and Selye, H., Blood picture during alarm reaction. Folia Haemat., 1939, 62, 397.

3. Forsham, P. H., Thorn, G. W., and Prunty, F. T. G., Clinical studies with pituitary adrenocorticotropin. J. Clin. Endocrinol., 1948, 8, 15.

4. Hills, A. G., Forsham, P. H., and Finch, C. A., Changes in circulating leukocytes induced by administration of pituitary adrenocorticotrophic hormone (ACTH) in man. Blood, 1948, 3, 755.

5. Thorn, G. W., Forsham, P. H., Prunty, F. T. G., and Hills, A. G., Test for adrenal cortical insufficiency; response to pituitary adrenocorticotropic hormone. J. A. M. A., 1948, 137, 1005 (correction, 1544).

6. Thorn, G. W., and Forsham, P. H., Clinical tests for adrenal cortical reserve, in Progress in Clinical Endocrinology, S. Soskin, Editor. Grune \& Stratton, New York, 1950, p. 213.

7. Hume, D. M., and Wittenstein, G. J., The relationship of the hypothalamus to pituitary-adrenocortical function, in Proceedings of the First Clinical ACTH Conference, J. R. Mote, Editor. Blakiston Co., Philadelphia, 1950, p. 134.

8. Hume, D. M., Role of the hypothalamus in pituitaryadrenal cortical response to stress. J. Clin. Invest., $1949,28,790$.

9. Recant, L., Hume, D. M., Forsham, P. H., and Thorn, G. W., Studies on the effect of epinephrine on the pituitary-adrenocortical system. J. Clin. Endocrinol., 1950, 10, 187.

10. Best, W. R., Samter, M., and Kark, R. M., The effect of adrenocortical stimulation on eosinophils of 
blood and bone marrow (abstract). Proc. Inst. Med. Chicago, 1950, 18, 120.

11. Best, W. R., and Samter, M., Variation and error of eosinophil counts of the blood and bone marrow. Blood, 1951, 6, 61.

12. Best, W. R., Muehrcke, R. C., and Kark, R. M., Studies on adrenocortical eosinopenia (abstract). J. Clin. Invest., 1951, 30, 629.

13. Best, W. R., Muehrcke, R. C., and Kark, R. M., Clinical and statistical evaluation of four-hour eosinophil response tests (abstract). J. Lab. \& Clin. Med., 1951, 38, 790.

14. Abelson, D., and Moyes, E. N., Ephedrine in a screening test for cortisone substitutes. Lancet, 1950, 2, 50.

15. Jailer, J. W., Wong, A. S. H., and Engle, E. T., Pituitary-adrenal relationship in full-term ard in premature infants, as evidenced by eosinophil response. J. Clin. Endocrinol., 1951, 11, 186.

16. Solomon, D. H., and Shock, N. W., Studies of adrenal cortical and anterior pituitary function in elderly men, in Proceedings of the First Clinical ACTH Conference, J. R. Mote, Editor. Blakiston Co., Philadelphia, 1950, p. 44.

17. Roche, M., Thorn, G. W., and Hills, A. G., The Levels of circulating eosinophils and their response in surgery; their use as an index of adrenocortical function. New England J. Med., 1950, 242, 307.

18. Smith, J. J., The blood eosinophil responses of the alcoholic to epinephrine and to ACTH, with a note on the treatment of chronic alcoholism with ACTH, in Proceedings of the Second Clinical ACTH Conference, Vol. II, J. R. Mote, Editor. Blakiston Co., Philadelphia, 1951, p. 161.

19. Wolfson, W. Q., and Cohn, C., The role of the pituitary adrenocorticotrophic hormone (ACTH) and of adrenal cortical steroid hormones in the pathological physiology and experimental therapeutics of clinical gout. Proceedings of the First Clinical ACTH Conference, J. R. Mote, Editor. Blakiston Co., Philadelphia, 1950, p. 241.

20. Randolph, T. G., Blood studies in allergy. I. The direct counting chamber determination of eosinophils in propylene-glycol-aqueous stains. J. Allergy, 1944, 15, 89.

21. Henneman, P. H., Wexler, H., and Westenhaver, $\mathbf{M}$. M., A comparison of eosin-acetone and phloxine- propylene glycol diluents in eosinophil counts. J. Lab. \& Clin. Med., 1949, 34, 1017.

22. Snedecor, G. W., Statistical Methods Applied to Experiments in Agriculture and Biology. The Collegiate Press, Inc., Ames, Iowa, 1946, 4th ed.

23. Fisher, B., and Fisher, E. R., Observations on the eosinophil count in man; a proposed test of adrenal cortical function. Am. J. M. Sc., 1951, 221, 121.

24. Berkson, J., Magath, T. B., and Hurn, M., The error of estimate of the blood cell count as made with the hemocytometer. Am. J. Physiol., 1940, 128, 309.

25. Sheehan, H. L., and Summers, V. K., The syndrome of hypopituitarism. Quart J. Med., 1949, 28, 319.

26. Rud, F., The eosinophil count in health and in mental disease; biometrical study. Acta psychiat. et neurol., 1947, Supp. 40.

27. Strauss, M. B., and Brokaw, R., Adrenocortical function in pernicious anemia. New England J. Med., 1951, 245, 796.

28. Renold, A. E., Forsham, P. H., Maisterrena, J., and Thorn, G. W., Intravenously administered ACTH; a preliminary report. New England J. Med., 1951, 244, 796.

29. Gaddum, J. H., and Kwiatkowski, H., The action of ephedrine. J. Physiol., 1938, 94, 87.

30. Sayers, G., Personal communication.

31. McDermott, W. V., Fry, E. G., Brobeck, J. R., and Long, C. N. H., Mechanism of control of adrenocorticotrophic hormone. Yale J. Biol. \& Med., 1950, 23, 52.

32. Sayers, G., Pituitary regulation of adrenal cortical activity, in Progress in Clinical Endocrinology, S. Soskin, Editor. Grune \& Stratton, New York, 1950, p. 122.

33. Robinson, W. H., Personal communication.

34. Muehrcke, R. C., Lewis, J. L., Peters, J. H., Best, W. R., and Kark, R. M., Mechanisms of adrenocortical eosinopenia: antagonisms between heparin and cortical hormones and the action of epinephrine post-adrenalectomy. Proc. Inst. Med. Chicago, 1952, 19, 68.

35. Almy, T. P., Laragh, J. H., and Cohen, E. J., Response of circulating eosinophils to epinephrine as an index of adrenal cortical function. New York Med., June 5, 1950, 6, 16. 